\title{
The Effect of Acetone Addition on the Properties of Epoxy
}

\author{
Marcio R. Loos, Luiz Antonio F. Coelho, Sérgio H. Pezzin \\ Centro de Ciências Tecnológicas, UDESC
}

\author{
Sandro C. Amico \\ DEMAT, PPGEM, UFRGS
}

\begin{abstract}
In this work, a varied amount of acetone was employed to dissolve an epoxy resin and then a route was followed to remove the acetone, simulating a frequently used method to disperse nanofillers in thermoset matrices. Analyses were then carried out to address the influence of residual acetone on the curing process and on the epoxy properties. The results showed a detrimental effect on the mechanical properties of the cured epoxy due to the presence of residual acetone and also a less brittle-like fracture of the specimen. Fourier transform infrared spectroscopy and thermogravimetric analyses were additionally used to characterize the cured resins and have also indicated the presence of a small amount of acetone. Nevertheless, rheological measurements indicated that $10.0 \mathrm{wt} . \%$ acetone addition on the resin causes a significant decrease in viscosity (around 50\%) which may promote a better dispersion of nanofillers.
\end{abstract}

Keywords: Acetone, epoxy, curing process, mechanical and physical properties.

\section{Introduction}

The addition of solvents to thermoset resins is a possible route to decrease resin viscosity, allowing a better distribution of fillers including, more recently, carbon nanotubes $(\mathrm{CNTs})^{[1-3]}$.

Although the use of a solvent is beneficial to filler dispersion, it originates difficulties related to solvent removal and the effect of residual solvent on resin characteristics. Thus, the optimal, i.e. minimum, amount of solvent must be identified and used, since even a small amount of solvent left on the matrix may be responsible for hindering the cross-linking process, being deleterious to the mechanical properties of the resin.

Lau et al. ${ }^{[4]}$ studied how traces of solvent may alter the epoxy cross-linking process. The authors demonstrated that the boiling point of solvents may be used as an attempt to establish a trend regarding the effect on thermal and mechanical properties of epoxy. The influence of the solvent was ultimately attributed to the different amount of unreacted epoxide groups and the extent of cure reaction. Hong and $\mathrm{Wu}^{[5]}$ studied the influence of different solvents on the curing process of epoxy and dicyandiamide. According to these authors, differential scanning calorimetry (DSC) analyses revealed that the presence of solvent in the epoxy resin results in lower curing exotherm, initial curing rate, reaction rate, reaction order and glass transition temperature. They also found the most significant changes for the solvents with higher boiling temperature.

Nevertheless, it is important to bear in mind that the use of a solvent is very important as a way to adequately prepare nanocomposites using CNTs as fillers in epoxy matrices ${ }^{[4,6,7]}$. This is a necessary step due to the high viscos- ity of the neat epoxy which makes the dispersion of these finely divided materials very challenging.

In this context, the goal of this work is to study the effect of acetone solvent on the curing process as well as on the properties of epoxy matrices. Thus, acetone/epoxy solutions of different acetone concentrations, namely $0.0,7.0,10.0$ or $13.0 \mathrm{wt} . \%$, were prepared and then subjected to a mild processing route to remove acetone. Viscosimetric, thermogravimetric, tensile and morphological tests were performed in order to evaluate possible changes in the samples. In addition, Fourier transform infrared spectroscopy (FTIR) analyses were also employed in the search for changes in their molecular structure.

\section{Experimental}

\section{Materials}

The epoxy resin and the hardener used were araldite GY 251 (diglycidylether of bisphenol A, DGEBA, Huntsmann) and aradur HY 956 (Huntsmann), respectively. Acetone (Quimidrol, 99.5\% purity) was the chosen solvent.

\section{Methodology}

A certain amount of acetone $(7.0,10.0$, or $13.0 \%$ of the resin weight) was added to the resin and the mixture was simultaneously sonicated in a Sonics Vibration $(500 \mathrm{~W})$ and magnetically stirred for an hour. The mixture was then subjected to heating at $50{ }^{\circ} \mathrm{C}$ for an hour and conditioned under vacuum for five hours. Finally, hardener was added to the mixture with a 5:1 (w/w) epoxy resin:hardener ratio and homogenized. The curing process took place at room tempera-

Autor para correspondência: Luiz A. F. Coelho, UDESC - Centro de Ciências Tecnológicas, Campus Universitário s/n, CP 631, Bairro Bom Retiro, 
ture for 24 hours under continuous vacuum. Samples without acetone, called $0.0 \mathrm{wt} . \%$ of acetone, were also prepared for comparison, using the same mixture and curing procedure.

\section{Sample characterization}

The viscosity of the epoxy/acetone mixtures was measured with the aid of a cone/plate apparatus (Brookfield CAP 2000). Thermogravimetric analyses (TGA) were conducted in a Netzsch (STA 449C) equipment, heating the samples from 15 to $900{ }^{\circ} \mathrm{C}$ at a heating rate of $10{ }^{\circ} \mathrm{C} / \mathrm{min}$ under nitrogen atmosphere. Fourier transform infrared spectroscopy (FTIR) analyses were conducted in a Perkin-Elmer Spectrum One B equipment with a resolution of $4 \mathrm{~cm}^{-1}$, from 4000 to $650 \mathrm{~cm}^{-1}$, on transmission mode.

Tensile tests, according to ASTM D638, were performed in a Universal Testing Machine Emic DL 3000, with a 500 $\mathrm{kgf}$ load-cell and a $5 \mathrm{~mm} / \mathrm{min}$ cross-head speed. Morphological characterization of the fractured surface of the samples was carried out via scanning electron microscopy - SEM (equipment Zeiss DSM $940 \mathrm{~A}$ at $15 \mathrm{kV}$ ).

\section{Results and Discussion}

\section{Viscosity}

The viscosity of the various epoxy/acetone solutions at $50{ }^{\circ} \mathrm{C}$ is shown in Figure 1. The $0.0 \mathrm{wt} . \%$ acetone (neat resin) curve shows a slight tendency to pseudoplastic behavior, that is the viscosity decreases with shear rate, whereas no clear trend was observed for the epoxy/acetone solutions in the studied range of shear rates and the small variation in viscosity appears to be within the experimental error and/or related to some volatilization of acetone during the experiment.

Nevertheless, comparing the neat epoxy with the other samples, it can be seen that the addition of acetone decreases, in up to $50 \%$, the viscosity of the resin, what is expected considering that the solvating effect of the solvent weaken inter-chain interactions ${ }^{[8]}$. Besides, the solution with $10 \%$ of

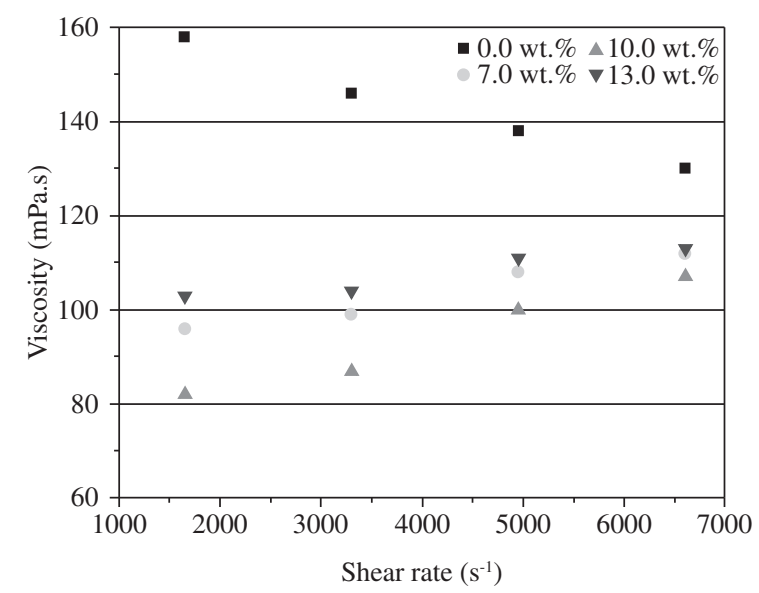

Figure 1. Viscosity of the samples with $0.0,7.0,10.0$ and 13.0 wt. $\%$ of acetone under different shear rates. acetone appears to show a slightly lower viscosity than the other samples for all shear rates tested.

\section{Infrared spectroscopy}

The FTIR spectra can provide information regarding changes in the molecular structure of the samples through the displacement, widening, appearance or lack of bands. As can be seen in Figure 2 for the various solutions in uncured state, the bands are quite similar, indicating that the use of acetone does not appear to change the chemical structure of the epoxy, similar to what has been suggested by $\mathrm{Lau}^{[4]}$.

The peaks specifically related to acetone ${ }^{[9,10]}$, $1708-1715 \mathrm{~cm}^{-1}$ (stretching of the $\mathrm{C}=\mathrm{O}$ ), $1731-1737 \mathrm{~cm}^{-1}$ (stretching of the gas phase of the $\mathrm{C}=\mathrm{O}$ ) and $3000-3005 \mathrm{~cm}^{-1}$ (stretching of the $\mathrm{C}=\mathrm{H}$ ) could not be separately identified due to superposition with epoxy related peaks, especially the absorptions due to the stretching of the $\mathrm{C}=\mathrm{O}$ and the $\mathrm{C}=\mathrm{H}$, at 1725 and $3005-3055 \mathrm{~cm}^{-1}$, respectively ${ }^{[4,11]}$.

The most characteristic absorptions of the uncured epoxy include a band around $910-920 \mathrm{~cm}^{-1[12-14]}$, due to the contraction of the $\mathrm{C}-\mathrm{C}$ bond and the stretching of both $\mathrm{C}-\mathrm{O}$ bonds, and a shoulder at $858 \mathrm{~cm}^{-1}$, due to the stretching of one $\mathrm{C}-\mathrm{O}$ bond and contraction of the other $\mathrm{C}-\mathrm{O}$ bond of the epoxide group $^{[4]}$. After curing, the former band decreases in intensity, shifts to higher values and may even split, whereas the shoulder disappears. Another reported feature of the cured epoxy may include the appearance of a band around $1650 \mathrm{~cm}^{-1} \mathrm{re}-$ lated to the formation of an imino group. A full list of epoxy infrared absorptions may be found in the work of $\mathrm{Lau}^{[4]}$.

The FTIR may give more insight into the role of acetone and for that, the band between $910-920 \mathrm{~cm}^{-1}$, was chosen as the reference band. Comparing the spectra of the cured and uncured resin, without acetone (Figure 3), it can be seen that the reference band disappears if the epoxy is fully cured. On the other hand, this band still remains for the samples with acetone, although it has been shifted from 910 to $925 \mathrm{~cm}^{-1}$ and decreased in intensity, compared to the uncured curve.

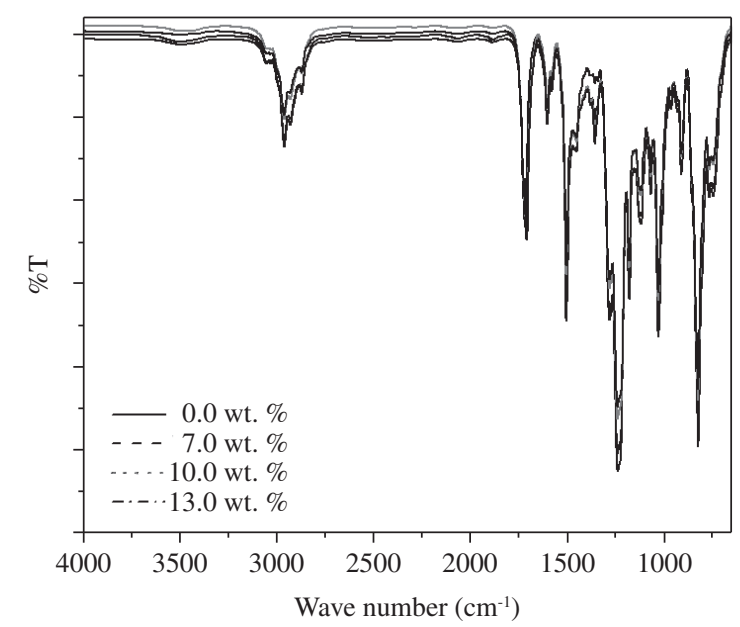

Figure 2. FTIR spectra obtained for the samples with 0.0, 7.0, 10.0, and $13.0 \mathrm{wt} . \%$ of acetone - uncured resin. 


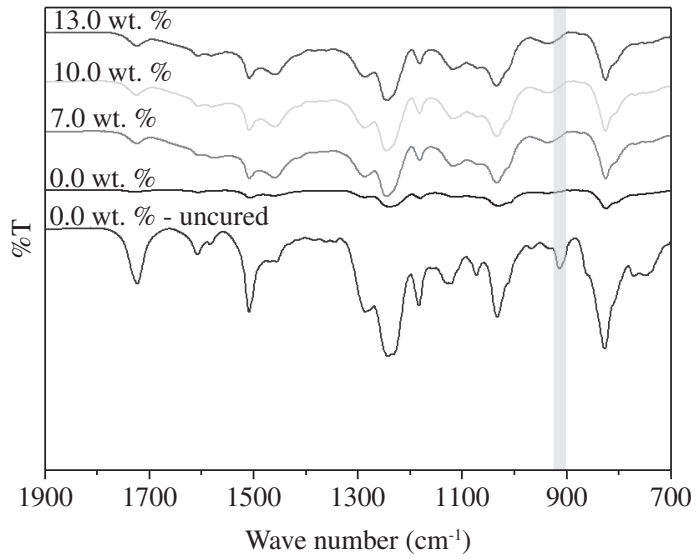

Figure 3. FTIR spectra obtained for the samples with 0.0, 7.0, 10.0, and $13.0 \mathrm{wt} . \%$ of acetone after the curing process.

This is an indication that there is acetone left on the epoxy resin which has affected the cross-linking process, decreasing the conversion degree of reactive groups ${ }^{[4,15]}$.

\section{Thermogravimetry}

Thermogravimetric analysis (Figure 4) of the neat cured epoxy ${ }^{[16]}$ has shown two major weight loss events in Figure 4a, the first, between $160-290{ }^{\circ} \mathrm{C}$ (peak at $240{ }^{\circ} \mathrm{C}$ in Figure 4b),

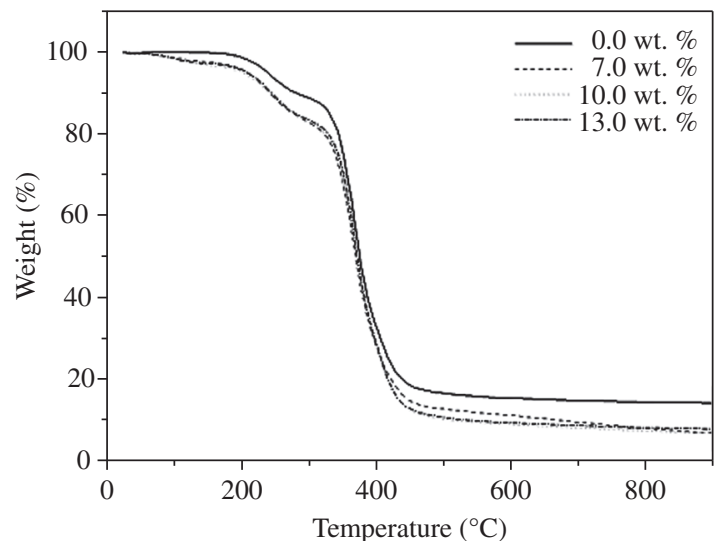

(a)

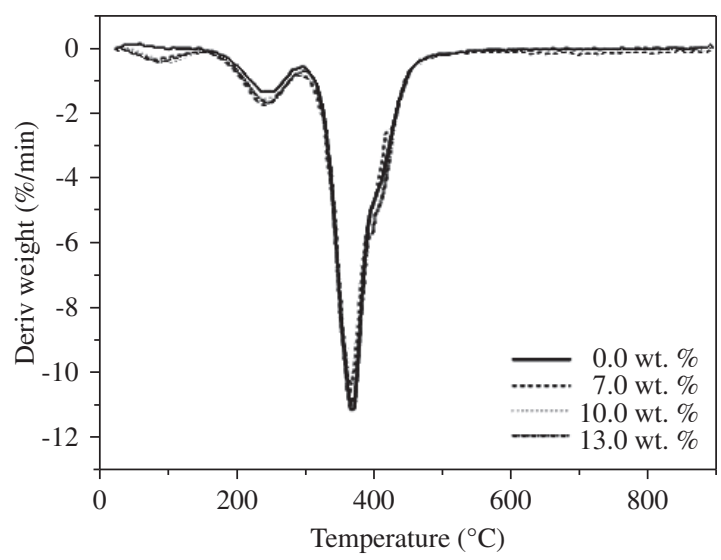

(b)

Figure 4. a) TG; and b) DTG curves for the samples with 0.0, 7.0, 10.0 and $13.0 \mathrm{wt} . \%$ of acetone. possibly due to the decomposition of lower molecular weight material, and the other one, between $290-490{ }^{\circ} \mathrm{C}$ (peak at $368^{\circ} \mathrm{C}$ in Figure $4 \mathrm{~b}$ ), referring to the degradation of the resin material ${ }^{[17]}$ of higher molecular weight formed during curing.

However, the TG curves obtained for the epoxy with acetone (Figure $4 \mathrm{a}$ ) have shown a different profile. There is an initial small weight loss, between $40-140{ }^{\circ} \mathrm{C}$ (peak at $89{ }^{\circ} \mathrm{C}$ in Figure $4 b$ ), corresponding to the evaporation of trapped solvent, a similar behavior to that reported by Sharmim ${ }^{[18]}$ for epoxy/dimethylsulphoxide solution. The derivative TG plot clearly shows the presence of this extra peak for the acetone cured epoxy resins.

Figures $4 \mathrm{a}, \mathrm{b}$ also indicate that the presence of acetone causes a increase in the intensity of the peak at $240{ }^{\circ} \mathrm{C}$. Besides, the weight loss in the range $160-290{ }^{\circ} \mathrm{C}$ increases from $5.2 \%$, for the neat resin, to around $9.7 \%$ for the other samples, which suggests that there is comparatively more material on lower molecular weight chains, which may undergo thermal degradation sooner. This can be attributed to the incomplete cure of the resin due to the presence of residual acetone, that affects the curing kinetics and, consequently, the structure of the epoxy resin ${ }^{[12]}$. The presence of acetone is likely to decrease the degree of cross-linking, increasing the chain molecular mobility, ultimately lowering the glass transition temperature ${ }^{[5]}$.

\section{Tensile properties}

Table 1 presents the tensile testing results of the different samples. It can be seen that the presence of acetone resulted in a decrease in Young's modulus, tensile strength and elongation at break of the epoxy resin. This effect was more pronounced for resins prepared with a higher acetone content, reaching a $16-21 \%$ decrease in these properties for the $13.0 \mathrm{wt} . \%$ acetone sample. The decrease in Young's modulus is particularly interesting in ratifying the findings regarding the mentioned lower degree of crosslinking of the resins in which acetone had been added. Mondragon ${ }^{[15]}$ also found for a DGEBA epoxy resin that the presence of a small amount of solvent (in their case $\mathrm{CH}_{2} \mathrm{Cl}_{2}$ ) at the beginning of the curing reaction, even if they are later lost by evaporation, have a measurable effect on curing kinetics and $\mathrm{T}_{\mathrm{g}}$ of the resin due to a modification of the network structure.

The decrease in tensile strength and elongation at break may be related to the presence of weakly bonded acetone rich areas of the resin which may act as stress concentration points.

Table 1. Tensile properties of the samples.

\begin{tabular}{cccc}
\hline $\begin{array}{c}\text { Acetone } \\
(\text { wt. \%) }\end{array}$ & $\begin{array}{c}\text { Young's } \\
\text { modulus } \\
(\mathbf{G P a})\end{array}$ & $\begin{array}{c}\text { Tensile } \\
\text { strength } \\
(\mathbf{M P a})\end{array}$ & $\begin{array}{c}\text { Elongation } \\
\text { at break } \\
(\boldsymbol{\%})\end{array}$ \\
\hline 0.0 & $2.5+0.3$ & $42.8+2.0$ & $2.8+0.4$ \\
7.0 & $2.3 \pm 0.1$ & $40.8 \pm 1.0$ & $2.5 \pm 0.4$ \\
10.0 & $2.2 \pm 0.4$ & $38.7 \pm 0.8$ & $2.5 \pm 0.4$ \\
13.0 & $2.1 \pm 0.2$ & $34.4 \pm 3.0$ & $2.2 \pm 0.4$ \\
\hline
\end{tabular}


This is in qualitative agreement with the work of Dickens ${ }^{[19]}$ who found that higher amount of residual acetone decreased strength and modulus (in flexure) of a particular thermoset resin, which was attributed in their case to the presence of defects in the specimen, such as porosity originated from acetone evaporation.

\section{Scanning electron microscopy}

SEM images of tensile fractured surfaces are presented in Figure 5. Figure 5a, for the sample which did not use solvent ( $0.0 \mathrm{wt} . \%$ acetone), has shown a typical fragile behavior, whereas for the 13.0 wt.\% acetone sample (Figure 5b,c), a

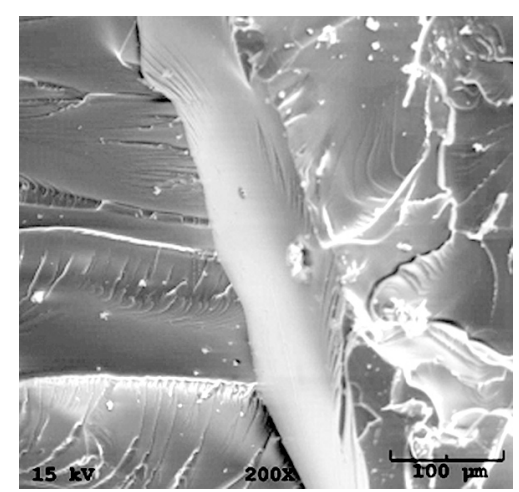

(a)

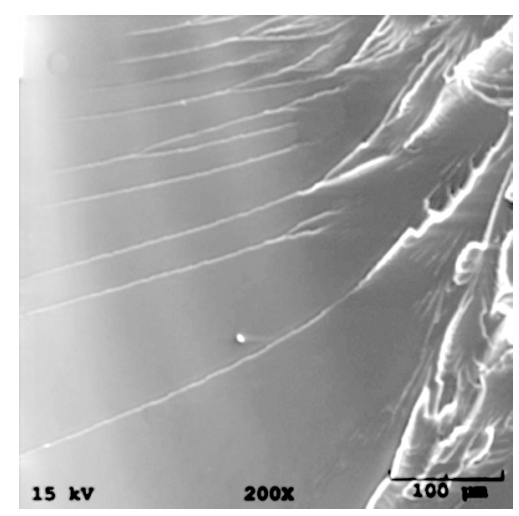

(b)

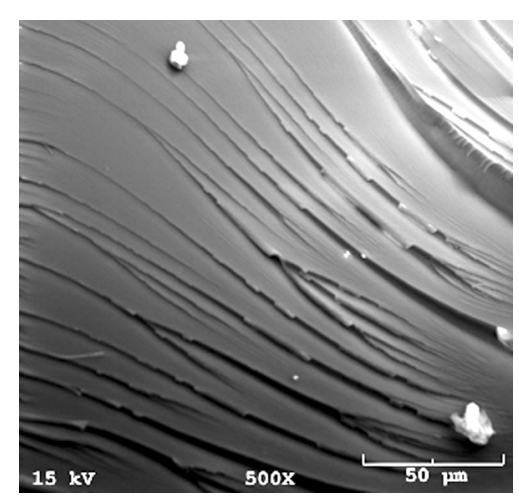

(c)

Figure 5. Micrograph of fractured samples with 0.0 (a) and 13.0 wt. \% of acetone at different magnifications, 200 and 500x (b and c respectively). less brittle-like fracture is observed. This may be compared to a less extent to the effect of moisture on saturated epoxy specimens, which show a transition to ductile behavior due to moisture-induced plasticization, i.e. from a brittle fracture mechanism such as crazing to a ductile mechanism such as bulk shear yielding ${ }^{[20]}$. This could explain some near circular or ellipsoid patterns left on the fractured surface of the 13.0 wt.\% acetone sample.

Furthermore, no apparent porosity was found in any of the micrographs taken, indicating that the difference in mechanical properties is indeed a consequence of alterations in the characteristics of the resin material.

\section{Conclusions}

The influence of the presence of residual solvent, namely acetone, on the characteristics of an epoxy resin was studied. It may be concluded that care must be exercised in order to ensure that all solvent is removed before curing, otherwise the cross-linking process is altered, leading to significant changes in physical and mechanical properties, for instance the Young's modulus, even if only a small amount of solvent is left on the matrix. The molecular strucuture of the cured resin has also been affected, as detected by FTIR analyses, and SEM micrographs showed a less brittle-like fracture for the material to which acetone had been added. Thermal degradation has also been affected by the acetone.

Nevertheless, a 50\% reduction in viscosity due to solvent solvating of the DGEBA molecules was found when $10 \mathrm{wt} . \%$ of acetone was added to the epoxy resin, which is very beneficial to processes where finely divided fillers are to be incorporated and dispersed into highly viscous polymer resins as a consequence of a stirring process, helping defining more suitable conditions for the preparation of epoxy nanocomposites with carbon nanotubes when following this solvent route.

\section{Acknowledgments}

The authors would like to thank CAPES-PROCAD (Project 0303054) for the financial support and for the scholarship to Mr. M. R. Loos.

\section{References}

1. Dong, B.; Yang, Z.; Huang, Y. \& Li, H.-L. - Tribol. Lett., 20, p.251 (2005).

2. Gong, X., Liu, J., Baskaran, S., Voise, R. D. \& Young, J. S. - Chem. Mater., 12, p.1049 (2000).

3. Puglia, D., Valentini, L., Armentano, I. \& Kenny, J. M. Diam. Relat. Mater., 12, p.827 (2003).

4. Lau, K. T., Lu, M., Lam, C. K., Cheung, H. Y., Sheng, F. L. \& Li, H. L. - Compos. Sci. Technol., 65, p.719 (2005). 
5. Hong, S. G. \& Wu, C. S. - J. Therm. Anal. Calorim., 59, p.711 (2000).

6. Liao, Y. H., Marietta-Tondin, O., Liang, Z. Y., Zhang, C. \& Wang, B. - Mat. Sci. Eng. A-Struct, 385, p.175 (2004).

7. Song, Y. S. \& Youn, J. R. - Carbon, 43, p.1378 (2005).

8. Qian, J. W., Miao, Y. M., Zhang, L. \& Chen, H. L. - J. Membrane Sci., 203, p.167 (2002).

9. Max, J. J. \& Chapados, C. - J. Chm. Phys., 126, Art. (2007).

10. Torii, H., Musso, M. \& Giorgini, M. G. - J Phys Chem A, 109, p.7797 (2005).

11. Lachenal, G., Pierre, A. \& Poisson, N. - Micron, 27, p.329 (1996).

12. Hong, S. G. \& Wu, C. S. - Thermochim. Acta, 316, p.167 (1998).

13. Yuan, L., Liang, G. Z., Xie, J. Q., Guo, J. \& Li, L. Polym. Degrad. Stabil., 91, p.2300 (2006).
14. Evtushenko, Y. M., Ivanov, V. M. \& Zaitsev, B. E. - J. Anal. Chem., 58, p.347 (2003).

15. Mondragon, I. \& Bucknall, C. B. - Plast. Rubber Compos., 21, p.275 (1994).

16. Park, S. J., Lee, H. Y., Han, M. \& Hong, S. K. - J. Colloid Interf. Sci., 270, p.288 (2004).

17. Gracia-Fernandez, C. A., Gomez-Barreiro, S., Ruiz-Salvador, S. \& Blaine, R. - Prog. Org. Coat., 54, p.332 (2005).

18. Sharmin, E., Imo, L., Ashraf, S. M. \& Ahmad, S. - Prog. Org. Coat., 50, p.47 (2004).

19. Dickens, S. H. \& Cho, B. H. - Dent. Mater., 21, p.354 (2005).

20. Lin, Y. C. \& Chen, X. - Mater. Lett., 59, p.3831 (2005).

Enviado: 07/06/07

Reenviado: 09/09/07

Aceito: 14/09/07 